\title{
Uso de Business Intelligence na Gestão de Recursos Hídricos: o caso da Fiscalização do Uso da Água
}

\author{
Damião Ribeiro de Almeida ${ }^{1}$, André Luiz Firmino Alves ${ }^{2}$, Cláudio De Souza \\ Baptista $^{1}$, Hugo Feitosa de Figueirêdo ${ }^{2}$, Pedro Crisóstomo Alves Freire ${ }^{3}$, Diego \\ Magno Tavares da Silva ${ }^{3}$

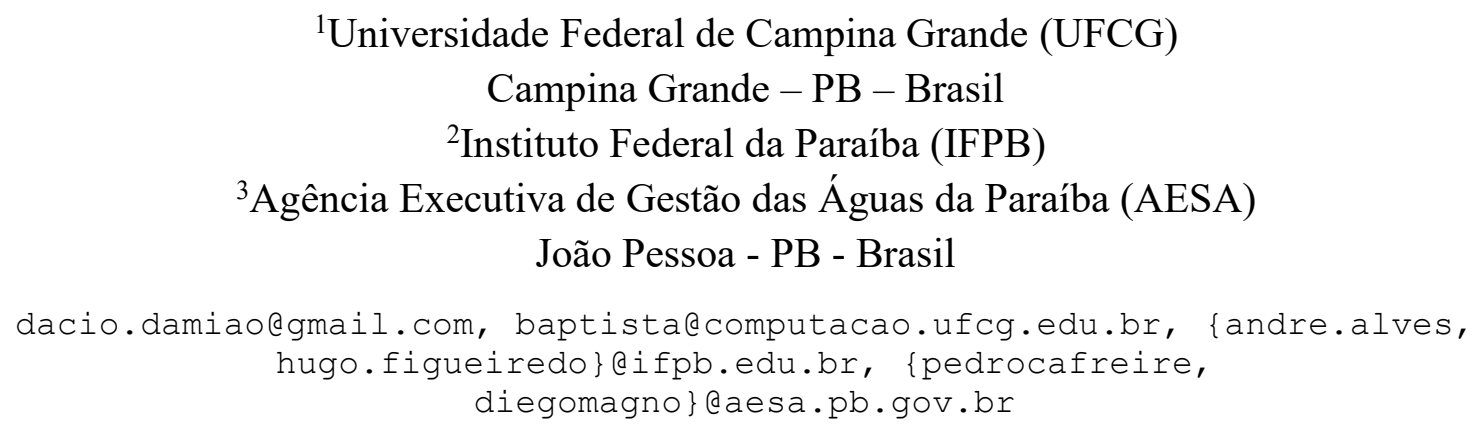

\begin{abstract}
Decision-making systems, when conceived and implemented in a correct way, have a positive impact on the decision support process, in particular on the management of water resources. Business Intelligence - BI technology allows the adoption of a management process in which data from the operating systems are extracted, transformed and loaded into the Datawarehouse, data cubes are created for analysis, and frontends implemented for performing the analysis in the form of charts, maps, tables and dashboards. This paper uses this important BI technology to implement a decision-making process for the control of water use. The decision support system that implements such a process is innovative and enables a more efficient and easier management of water resources.
\end{abstract}

Resumo. Sistemas de apoio à decisão, quando concebidos e implantados de forma correta, acarretam em um impacto positivo no processo de apoio à decisão, em particular na gestão de recursos hídricos. A tecnologia de Business Intelligence - BI permite a adoção de um processo gerencial no qual, dados dos sistemas operacionais são extraídos, transformados e carregados no Datawarehouse, criam-se cubos de dados para realização das análises e frontends para realização da análise em forma de gráficos, mapas, tabelas e painéis. Este artigo utiliza-se desta importante tecnologia de BI, para implantar um processo decisório para a fiscalização do uso da água. O sistema de apoio decisão que implementa tal processo é inovador e habilita uma gestão mais eficaz e facilitada dos recursos hídricos.

\section{Introdução}

$\mathrm{Na}$ hodierna era da informação, atesta-se um crescimento exponencial na geração e coleta de dados por diversos tipos de sensores. Entretanto, tal tsunami de dados não tem se revertido em conhecimento que possa fazer um diferencial no processo de tomada de decisão em empresas e órgãos governamentais. Ademais, esta diversidade de bancos de dados resulta na existência de dados conflitantes que levam a informações inconsistentes, dificultando um processo de tomada de decisão rápido e correto. 
Por outro lado, as empresas e órgãos públicos precisam tomar decisões ágeis, corretas, tempestivas e facilmente acessíveis. Para tanto, é mister o uso de ferramentas de análise para o suporte à decisão. Business Intelligence (BI) endereça esta demanda de forma a promover integração, usabilidade e eficiência na extração de conhecimento de grandes volumes de dados. BI é um conjunto de metodologias, processos, e tecnologias que transformam dados brutos em informação útil para o processo de tomada de decisão.

Em Recursos Hídricos, este cenário não é diferente, pois são gerados e armazenados uma pletora de dados, os quais encontram-se espalhados em diversas bases e utilizados parcialmente por sistemas de informação no nível operacional, não trazendo resultados nos níveis gerencial e estratégico. Destarte, o uso de ferramentas de suporte ao apoio à decisão, como as ferramentas de BI, na gestão de recursos hídricos, é um avanço tecnológico que propicia ao gestor decisões mais eficientes e eficazes (Baltar 2001)(Peixinho e Melo, 2012).

Neste artigo, apresenta-se uma ferramenta de apoio à decisão, usando BI, para gestão de recursos hídricos no âmbito da físcalização do uso regularizado da água. A fiscalização visa reduzir o uso não autorizado - ilegal - da água na Paraíba. Este trabalho é pioneiro, uma vez que não foi encontrado na literatura uma pesquisa similar que proponha um sistema de apoio à decisão (SAD) na fiscalização do uso da água.

$\mathrm{O}$ restante deste artigo está estruturado conforme segue. Na seção 2 são discutidos os trabalhos relacionados. A seção 3 discorre sobre o processo de BI e sua aplicação na gestão dos recursos hídricos. A seção 4 foca no processo de apoio à decisão. Na seção 5 apresenta-se a arquitetura do SAD e discutem-se aspectos de sua implementação. Na seção 6, são apresentadas as conclusões e trabalhos futuros.

\section{Trabalhos Relacionados}

Existem vários trabalhos de pesquisa que abordam a temática de uso de $\mathrm{SAD}$ em Recursos Hídricos. Baltar (2001) propôs um SAD para análise integrada da alocação de recursos hídricos perfazendo o impacto econômico ao longo prazo das mais diversas decisões, desde a construção de infra-estrutura hidráulica até a definição de regras de gerenciamento da demanda dos recursos hídricos. Peixinho e Mello (2012) propõem a utilização de $B I$ na área de recursos hídricos subterrâneos. A proposta envolve utilizar bases de dados provenientes do SIAGAS (Sistema de Informações de Águas Subterrâneas), enriquecer os dados com critérios de negócio, construir um Data Store Operacional (ODS) para integrar os dados relevantes e elaboração da análise de negócio através da confecção de dashboards. Collischonn (2014) desenvolveu um SAD para oferecer suporte aos pedidos de outorga seguindo a legislação brasileira, possibilitando a integração do gerenciamento do balanço hídrico em bacias de múltiplos domínio.

Em edições anteriores do WCAMA, alguns artigos trataram de métodos para auxiliar na gestão de recursos naturais que utilizavam sistemas de informação para facilitar a implantação do processo. Um sistema de apoio à análise da vulnerabilidade natural à poluição de recursos hídricos foi desenvolvido por Marques et al. (2009). Utilizando lógica fuzzy, Oliveira e Zeilhofer (2017) desenvolveram um SAD para outorga de recursos hídricos. Meier, Costa e Basso (2015) descreveram a importância da participação da sociedade na gestão de recursos hídricos, destacando a legislação brasileira e portuguesa. A FUNCEME (Sakamoto et al., 2016) desenvolveu sistema de informação para auxiliar na tomada de decisão pelo setor agrícola utilizando uma base 
de dados sobre gestão de recursos hídricos. Pereira e Cavalcanti (2016) propuseram um SAD para gestão de recursos hídricos, o qual utiliza informações da rede de fluxo hídrica, dos reservatórios, das demandas e afluentes para realizar simulações.

Como observado, não foram encontrados trabalhos na literatura que tenha proposto um método para apoiar as decisões no contexto de fiscalização do uso de recursos hídricos, possibilitando o cumprimento da legislação, que é o foco deste artigo.

\section{Business Intelligence (BI) - Visão Geral}

A informação é basilar para o apoio à decisão executiva, sendo matéria prima para obtenção do conhecimento, essencial ao processo de tomada de decisão. A informação está nos níveis operacional e gerencial. No nível operacional, a informação é combustível para que os sistemas no nível operacional funcionem. No âmbito de Gestão de Recursos Hídricos, sistemas de outorga, licença de obra hídrica, físcalização de uso da água, operação de reservatórios, segurança de barragens e sistema de monitoramento hidroclimatológico, são exemplos de sistemas operacionais. No nível gerencial, a informação alimenta os processos de tomada de decisão, voltadas, por exemplo, ao planejamento e processo de controle de áreas específicas. Na gestão das águas, a informação gerencial pode elencar, por exemplo, as áreas que estão com maiores demandas de fiscalização, o quantitativo de outorgas por bacia, bacias que estão saturadas do ponto de vista do balanço hídrico, dentre outros.

Para um bom projeto de um SAD, requer-se do executivo o seu envolvimento na especificação do mesmo. Para tanto, o executivo deve conhecer os processos decisórios, identificar os objetivos do processo de planejamento e das políticas existentes; identificar as necessidades de informação que visem auxiliar no processo decisório; e correlacionar as informações com o nível decisório.

Um bom SAD deve lidar com a informação correta, precisa, relevante e completa; de forma tempestiva; no formato correto que seja de fácil entendimento e manipulação; e com um custo correto que leve a um bom custo/benefício e rápido retorno de investimento. Existem ao menos dois fatores que auxiliam o executivo na sua decisão: a corretude das informações que subsidiam o processo decisório e a rapidez com a qual se identificam oportunidades e ameaças. Certamente, exige-se da empresa ou órgão governamental um planejamento estratégico para apoiar as decisões e planejamento, adequando-se às intempéries que surgem ao longo do percurso.

O processo de implantação de um SAD traz consigo uma percepção do real cenário da empresa ou órgão governamental, de forma rápida e intuitiva, através dos relatórios dinâmicos e painéis (dashboards); permitindo o cruzamento de informações para análise, visualização dos dados na forma de tabelas, gráficos, mapas e painéis de forma integrada, e implantação de pró-atividade no dia a dia do executivo.

Um bom projeto de BI combina várias tecnologias/processos: um processo de ETC (Extração, Transformação e Carga dos dados), Datawarehousing (DW), um processo analítico conhecido como OLAP (Online Analytical Processing); técnicas de Mineração de Dados para predição de cenários, ferramentas de visualização (dashboards) e geração de relatórios dinâmicos.No processo de ETC ocorre a extração, transformação, limpeza, agregação e carga dos dados advindos de sistemas OLTP (Online Transaction Processing), que são armazenado no datawarehouse. 
O DW provê uma infraestrutura para os usuários processarem de forma eficiente consultas analíticas [Vaisman e Zimányi, 2014]. Trata-se de um repositório que integra dados operacionais de diversas fontes. Um DW é um conjunto de dados orientados por assunto; não volátil; variável no tempo e integrado, criado para o suporte à decisão. Ser orientado por assunto significa que os dados são organizados por domínio e não por aplicações. A não volatilidade diz respeito aos dados serem dificilmente alterados, havendo praticamente a carga e consulta aos dados. Ser variável com o tempo indica que o DW é um banco de dados histórico. Por fim, a integração indica que os dados do DW devem estar homogeneizados de forma a eliminar inconsistências.

O projeto de um DW é essencialmente um modelo multidimensional. Não há nenhum modelo conceitual largamente utilizado em DW. Então, normalmente, modelase um DW no nível lógico relacional. Neste nível, o modelo multidimensional é normalmente representado por tabelas organizadas na forma de star schemas (estrela) e snowflake schemas (floco de neve). Estes esquemas relacionam uma tabela de fatos a várias tabelas de dimensões. Esquemas estrelas usam uma única tabela por dimensão, mesmo na presença de hierarquias (tabelas desnormalizadas). Esquemas snowflakes usam tabelas normalizadas para dimensões e suas hierarquias. Sobre esta representação relacional do DW, um servidor OLAP constrói um cubo de dados, que provê a visão multidimensional dos dados.

Na mineração de dados, são aplicadas técnicas de classificação supervisionada e não supervisionada para predição de cenários, visando o apoio à tomada de decisão.

Por fim, a camada de interface com o usuário é formada por painéis (dashboards), contendo gráficos, mapas, tabelas e gauges que fornecem ao executivo uma visão gerencial dos dados, com uso de KPI (Key Performance Indicators) para bater as metas planejadas e auxiliar na visualização da informação.

\section{Metodologia Proposta}

A ferramenta de apoio à decisão para fiscalização do uso da água tem como objetivo monitorar a inspeção dos recursos hídricos do estado. $O$ agente de fiscalização é responsável por ir a campo motivado tanto por uma denúncia quanto por uma constatação de uma irregularidade no sistema. Se for constatada a irregularidade, o agente pode emitir um auto de constatação ou um termo de compromisso. O primeiro informa que o usuário da água bruta comprometeu-se a regularizar a sua situação perante a AESA até uma data específica. O segundo indica que os recursos não estão sendo mais usados pelo usuário, ou que ele comprometeu-se em cessar as atividades de extração da água ou outra atividade relacionada aos recursos hídricos, como construção de açude, barragem ou despejo de substâncias em algum manancial. Dependendo da situação, o agente pode emitir uma multa através de um auto de infração ou realizar uma intervenção, ou seja, lacrando ou confiscando a bomba de extração de água. O esquema no banco de dados que representa esse universo é mostrado resumidamente na Figura 1.

A arquitetura de um $D W$ consiste em várias camadas: data sources, back-end, $D W$, OLAP e frontend (figura 4). Data sources consistem no armazenamento de dados a nível operacional, que pode ser um SGBD, arquivos internos do sistema ou outras fontes de dados na Internet. No sistema de fiscalização aqui proposto foi utilizado o banco de dados Postgresql 9.5, juntamente com a expansão espacial Postgis 2.3. A camada back-end consiste no processo ETC, que neste caso foi implementado no SGDB 
SQL Server, usando a ferramenta SQL Server Integration Service (SSIS). Por fim, a camada OLAP consiste no servidor em que o cubo multidimensional é armazenado e disponibilizado pelos sistemas da camada de frontend. Para a construção do cubo OLAP foi utilizada a ferramenta SQL Server Analysis Services (SSAS) e o Power BI como frontend para realizar as operações de análise no cubo multidimensional.

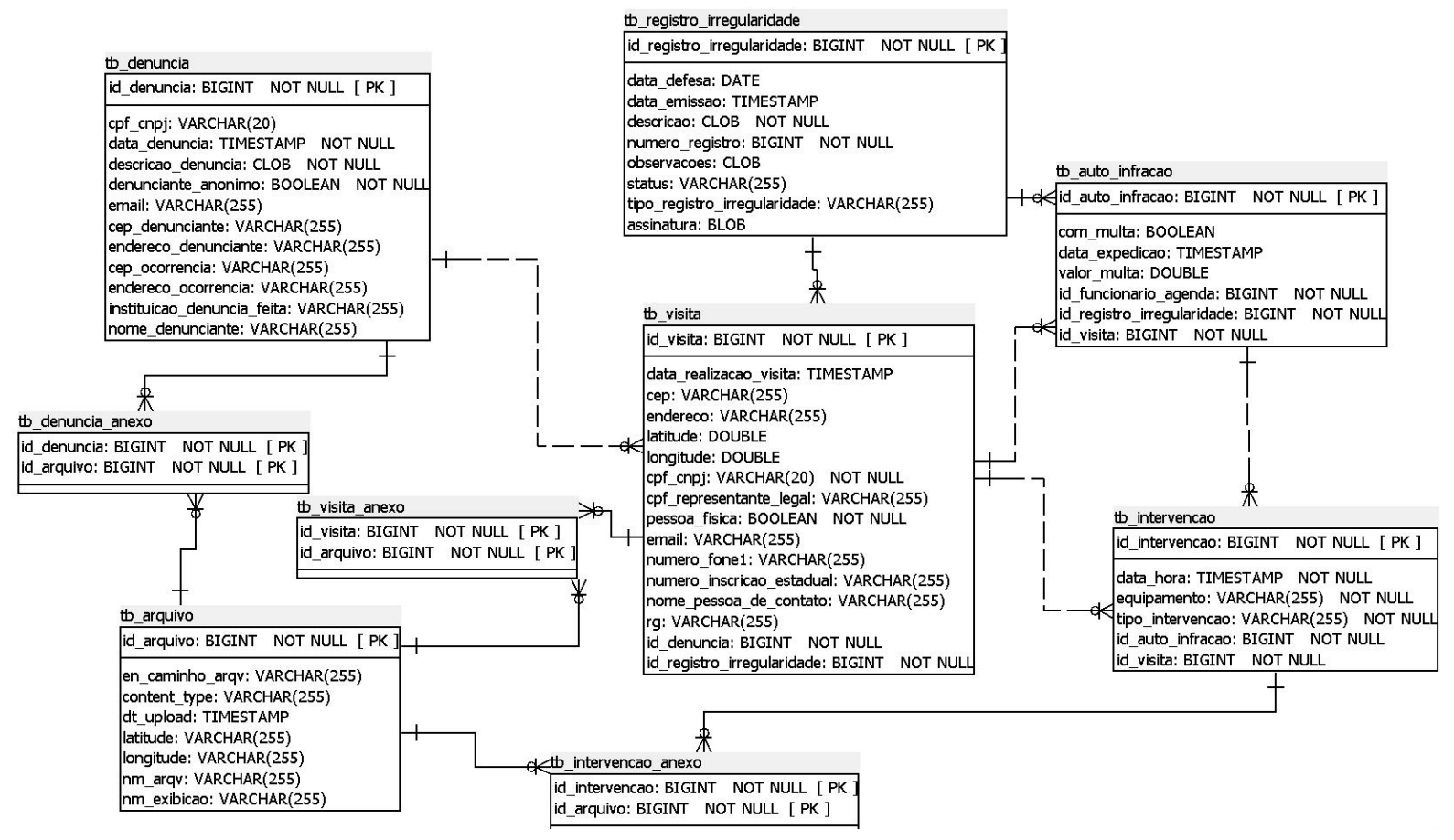

Figura 1 - Esquema do banco de dados

Antes de descrever o processo de ETL para o BI de fiscalização, é preciso detalhar o esquema de $D W$. Neste esquema são definidas as medidas nos fatos e as dimensões do esquema do $D W$. A Figura 2 mostra o esquema conceitual formado por duas tabelas de fato: a de visita que contém a informação de multa cobrada, caso tenha sido detectada alguma irregularidade; e a tabela de intervenção que informa o tipo de intervenção aplicada durante uma visita ao local de inspeção. A intervenção pode ser provisória ou permanente. As dimensões consistem em localização, denúncia e data de realização. A dimensão de localização é uma hierarquia que, além de possuir a localização geográfica da inspeção (coordenadas de latitude e longitude), é composta pelo município e estado. Denúncia e registro de irregularidade são dimensões não balanceadas uma vez que nem toda visita ocorre por causa de uma denúncia, o mesmo vale para registro de irregularidade [Vaisman e Zimányi, 2014]. A dimensão de tempo é composta por uma hierarquia formada pelas entidades data, mês e ano.

Com base no esquema do $D W$, foi desenvolvido o processo ETC conforme exibido na Figura 3. A etapa Clean $D W$ realiza a limpeza do banco $D W$, em seguida, o ETC inicia o processo de construção das dimensões do DW, que são localização (City Load), tempo (Time Load), registro de irregularidade (Registro irr Load) e denúncia (Denuncia Load). Todos esses processos são iniciados em paralelo, porém, a carga nas tabelas de fatos (Fato visita Load e Fato intervencao Load) só é realizada depois que a carga de todas as dimensões for finalizada. 
O processo de carga na tabela de fatos consiste basicamente em fazer uma junção com todas as dimensões que foram carregadas no DW. Cada tabela, além de possuir uma surrogate key, possui a chave primária natural que foi extraída do banco de dados no nível operacional. Através dessa chave primária, é realizada a operação de join entre a visita e as dimensões. Conforme é mostrado na Figura 3, a primeira etapa consiste em extrair dos dados da fonte de dados de operação através de um plugin ODBC. Para realizar o join com a dimensão de tempo, é preciso extrair as informações de dia, mês e ano da tabela de visita. Depois é realizado o join com a dimensão de localidade através do processo "lookup cities". Esse processo de lookup consulta a tabela de municípios com base na localização da visita. As informações de multa são extraídas da tabela de auto de infração. Esse processo é realizado pelo componente "Fonte ODBC auto_infracao" o qual soma todas as multas referentes a uma visita. Após o join com os dados de visita, o processo ETC descreve os passos para unir as dimensões registro de irregularidade e denúncia, cujo processo é semelhante aos demais: consulta as tabelas e realiza o join através da chave primária natural.

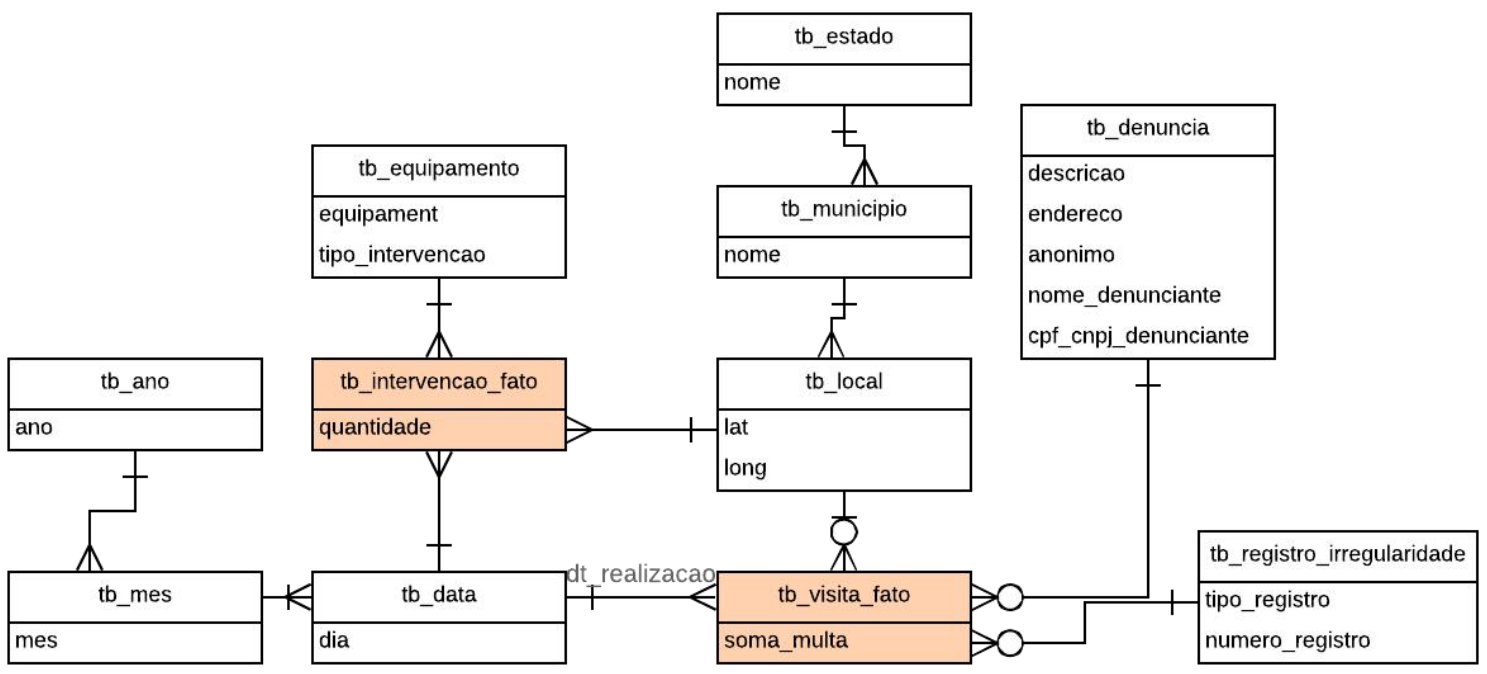

Figura 2 - Esquema conceitual do DW

Finalizada a construção do DW, a ferramenta de OLAP server auxilia no processo de construção do cubo dimensional e implantação do mesmo para ser consultado por qualquer aplicativo na camada de frontend. Foram então construídos dois cubos: um para visita de fiscalização e outro para intervenção.

\section{Arquitetura do Sistema de Apoio à Decisão de Fiscalização}

O SAD para o processo de fiscalização de uso da água segue a arquitetura mostrada na Figura 4. A camada de fonte de dados (data source) é onde os dados operacionais são armazenados. A arquitetura do sistema de fiscalização é dividida em três camadas:

- Camada de Frontend (Web / Dispositivos Móveis): responsável por interagir diretamente com o usuário do sistema mediante o uso de um navegador web, ou smartphone com aplicativo PowerBI conectado à internet. Nesta camada é possível observar o uso das tecnologias JSF 2.2 e Primefaces 5.3 ou 6.0. Alguns 
sistemas também apresentam versões de aplicativos móveis para auxiliar na coleta de dados em campo, como o sistema de fiscalização

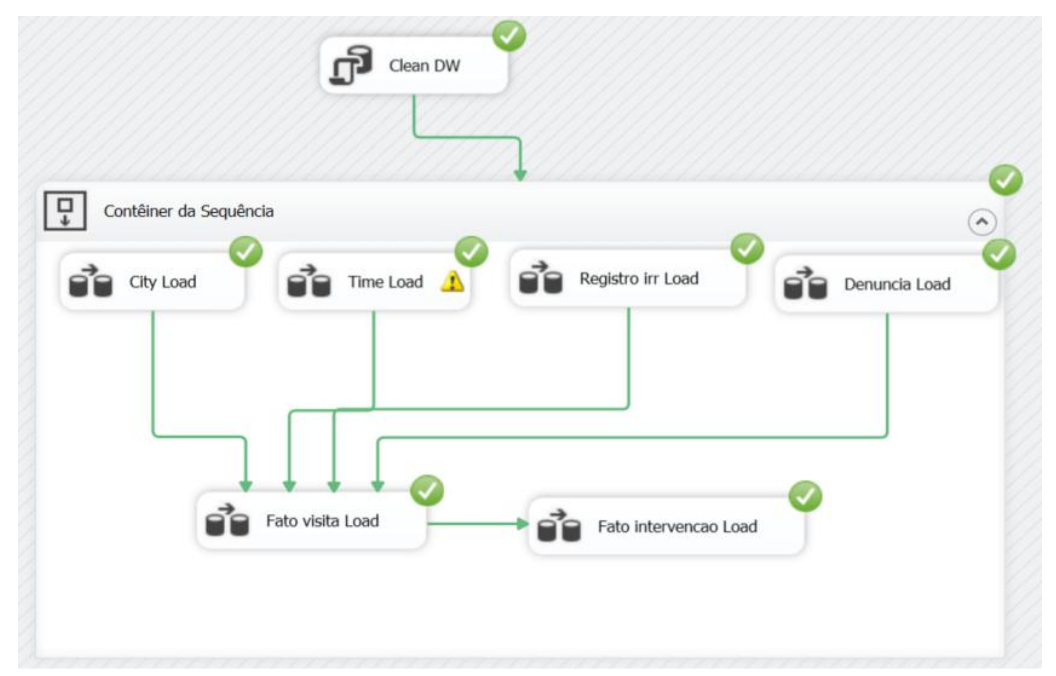

Figura 3 - Processo ETC

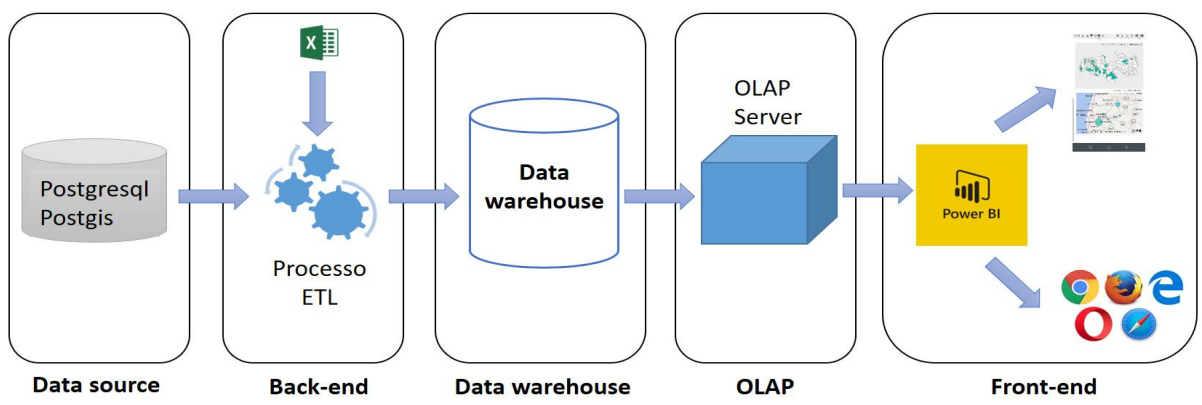

Figura 4 - Arquitetura do BI de Fiscalização

- Camada de Aplicação: provê toda a funcionalidade do sistema. Está subdividida em: Camada de Negócios: está subdividida em módulos de modo a melhor distribuir responsabilidades; ManagedBeans: intermedia a interação entre a camada de apresentação e as funcionalidades do sistema; Entidades do negócio: representa o domínio da lógica de negócio; Serviços: responsável por prover de fato as funcionalidades do sistema; e Acesso aos Dados: responsável por abstrair o acesso ao banco através do uso do padrão de projeto DAO e uso das tecnologias JPA 2.1 e Hibernate.

- Camada de Dados: responsável por armazenar os dados e manter o controle dos usuários que têm acesso ao sistema. O SGBD utilizado é o PostgreSQL 9, acrescentado do pacote de expansão de dados espaciais PostGIS 2.

Além de consultar a fonte de dados Postgresql, o processo de ETC consulta um arquivo XLS contendo todas as datas entre 2015 e 2019. Esse arquivo auxilia na construção da dimensão de tempo necessária para montagem do DW. O BI de Fiscalização está em processo de implantação, porém é de uso restrito da AESA. 


\subsection{Painéis (Dashboards) Web e Móvel}

A ferramenta de análise provê uma visão geral do alcance e impacto das informações coletadas sobre fiscalização de uso da água. A Figura 6 mostra um dashboard construído através do cubo de visitas. O dashboard mostra o número total de visitas: 248. Através do filtro temporal, o gerente pode visualizar as informações do dashboard referente a uma faixa de tempo específica: um ano específico, último semestre, últimos 3 meses, etc. A tabela mostra a relação de municípios do estado e quantidade de visitas realizadas em cada um. Essa informação também pode ser observada no mapa de quantidade de visitas. Quanto mais visitas mais vermelho é o preenchimento do município. A cor amarela significa que a quantidade de visitas está na média e a cor verde indica que a quantidade de visitas realizadas naquele município é baixa.

Outra informação importante é o total de multa que já foi arrecadado em cada município. Além do gráfico de barras que mostra o total arrecadado em cada município, o mapa de multas mostra, na forma de círculos, quais os pontos de captação de água em que houve alguma cobrança de pena devida alguma infração cometida. Quanto maior o valor da cobrança, maior é o círculo do ponto. O gráfico de pizza informa o tipo de registro de irregularidade que pode ocorrer em uma visita de fiscalização: termo de compromisso ou auto de constatação. O termo de compromisso significa que o usuário da água bruta comprometeu-se a regularizar a situação até um prazo especificado. $\mathrm{O}$ auto de constatação significa que a irregularidade foi resolvida no local ou o usuário comprometeu-se a resolver a situação rapidamente sem precisar de trâmites judiciais. Caso o usuário não obedeça ao compromisso estabelecido, o técnico de fiscalização pode emitir a multa ou confiscar o equipamento.

O dashboard da figura 6 apresenta as informações de intervenção. As intervenções podem ser de dois tipos: definitiva ou provisória. A intervenção definitiva significa que não há como voltar atrás na punição empregada, seja no confisco da bomba de extração de água ou no lacre da mesma. A intervenção provisória significa que a punição é temporária até que o usuário regularize a sua situação na Agência de Águas do Estado. $\mathrm{O}$ gráfico de barras informa o número de intervenções aplicadas por município. Quando o gerente clica em um município específico no gráfico, o mapa centraliza nas intervenções existentes naquele local.

A figura 7 mostra o frontend do SAD em plataforma móvel, provendo aos executivos uma visão gerencial do processo de fiscalização do uso da água em qualquer lugar e a qualquer momento, através do uso de um smartphone.

\section{Conclusões e Trabalhos Futuros}

A água doce requer uma atenção especial das autoridades, demandando uma gestão dos recursos hídricos eficiente e eficaz. Sistemas no nível operacional como Outorga e Licença de Obra Hídrica; Operação de Reservatórios; Monitoramento Hidrometereológico; Monitoramento da Qualidade da Água e Fiscalização do Uso da Água, formam a base mínima necessária a uma boa gestão do uso da água. No entanto, para uma gestão mais moderna, faz-se necessária a implantação de sistemas de apoio à decisão, trazendo uma visão estratégica e gerencial para os recursos hídricos, melhorando o planejamento e execução de ações. 


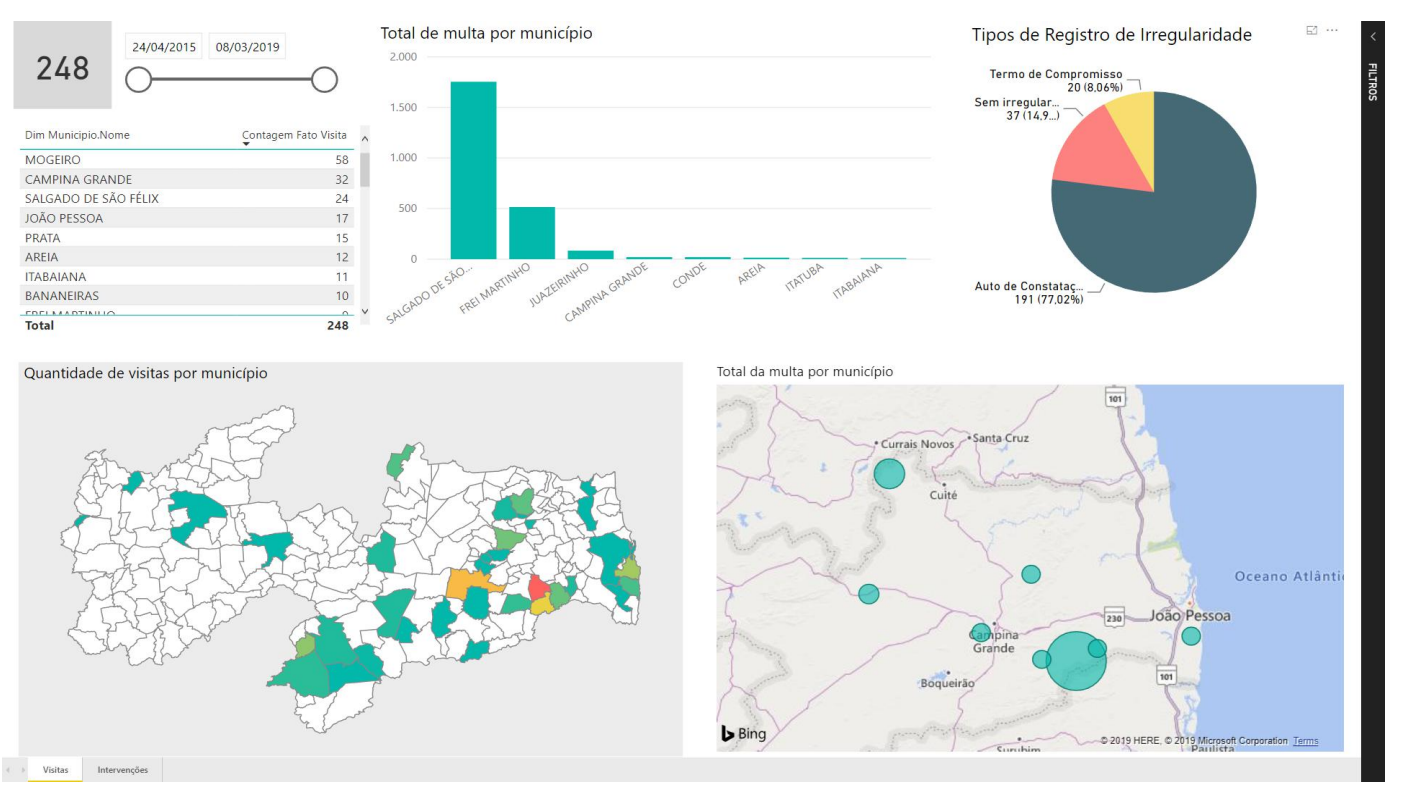

Figura 5 - Dashboard do cubo multidimensional de visitas

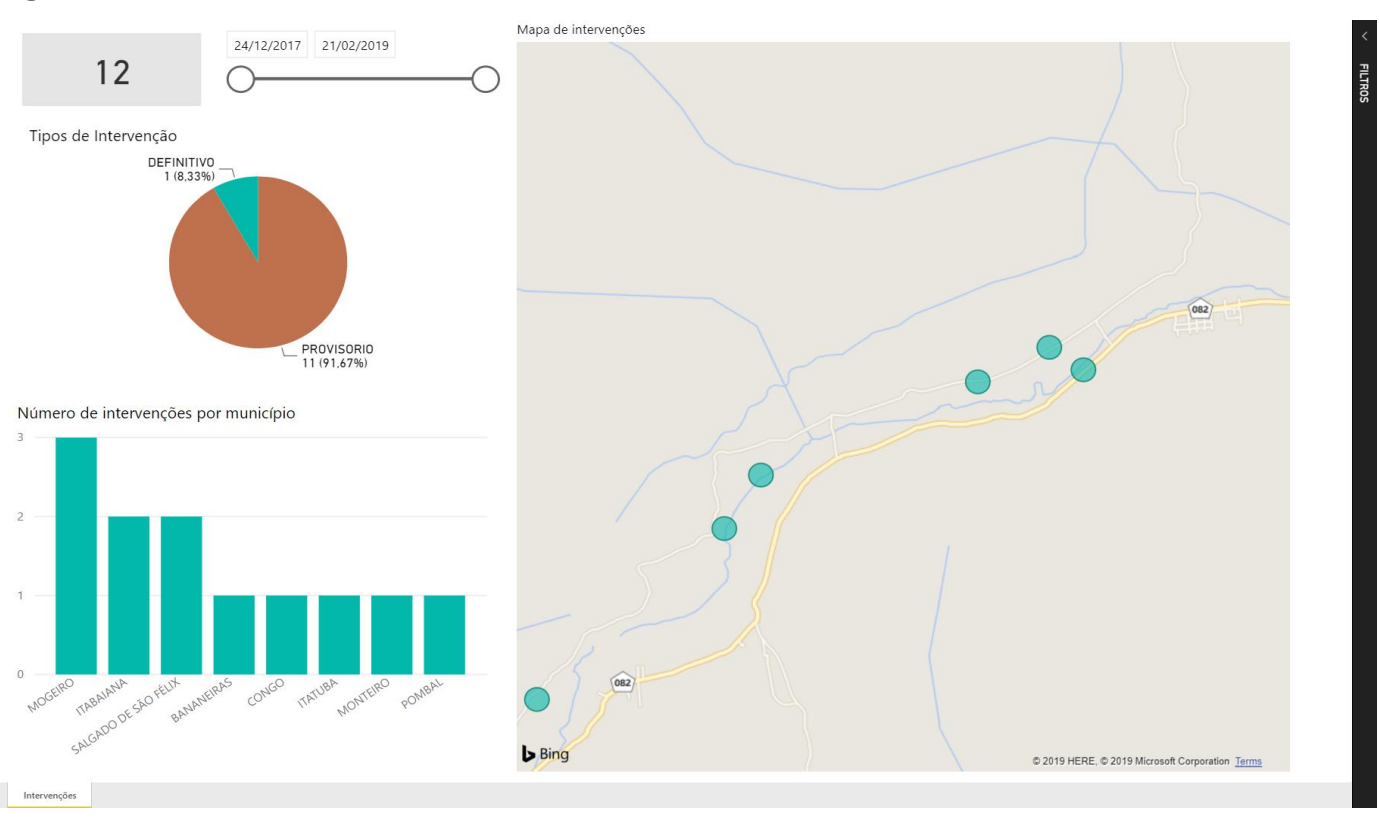

Figura 6 - Dashboard do cubo multidimensional de intervenções

A fiscalização do uso da água é um importante ator neste processo, uma vez que identifica os usuários que estão utilizando água de forma irregular. Neste artigo, apresentamos um processo inovador para um SAD para fiscalização do uso da água, baseada em tecnologias de BI, utilizando-se de dados geoespaciais e com interfaces de BI para Web e plataforma móvel. Foi apresentado e discutido um processo completo de BI, envolvendo o ETC, modelagem de um DW, criação de cubos e do frontend. Uma investigação feita na literatura mostrou que tal sistema aqui proposto é inovador.

O SAD aqui proposto encontra-se em fase de implantação na AESA, e um estudo do impacto na fiscalização que suas funcionalidades trazem será algo de uma investigação futura, como também a integração do SAD de fiscalização do uso da água com o SAD de Outorga, resultando numa visão sistêmica, à nível gerencial, destas duas áreas da gestão dos Recursos Hídricos. 


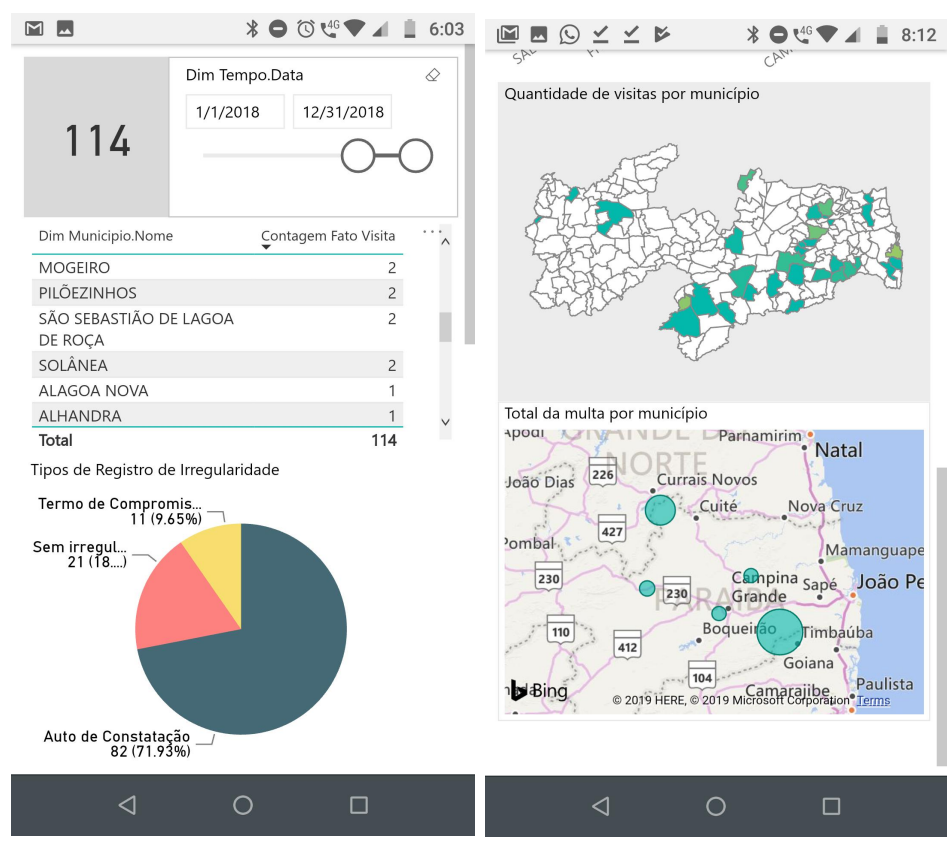

Figura 7 - Dashboard de Fiscalização em plataforma móvel

\section{Agradecimentos} pesquisa.

Os autores agradecem ao $\mathrm{CNPq}$ e a AESA por parcialmente financiar esta

\section{Referências}

Baltar, A.M. (2001) "Sistema de Apoio à Decisão para Avaliação Econômica da Alocação de Recursos Hídricos: Aplicação à Bacia da Barragem do Rio Descoberto". Dissertação de Mestrado em Tecnologia Ambiental e Recursos Hídricos, UNB.

Collischonn, B. (2014) "Sistema de Apoio à Decisão para Outorga de Direito de Uso de Recursos Hídricos". Tese de Doutorado do Programa de Pós-Graduação em Recursos Hídricos e Saneamento Ambiental da Universidade Federal do Rio Grande do Sul.

Marques, C.M., Guilherme, I.R., Foster, E.G., Assis, E.R.N., Meaulo, F.J. (2009) "Sistema de apoio à análise da vulnerabilidade natural à poluição do recurso hídrico subterrânea". WCAMA 2009.

Meier, M. A., Costa, F. S., Basso, L. A. (2015) “A Participação Social Na Gestão Dos Recursos Hídricos: Um Paralelo Entre Brasil E Portugal”, In: $12^{\circ}$ SILUSBA, Brasília.

Oliveira, C.U.R., Zeilhofer, P. (2017) "Sistema de Suporte à Decisão baseado em Lógica Fuzzy para Outorga de Recursos Hídricos Superficiais". In: WCAMA 2017.

Peixinho, F. C., Mello, F.L. (2012) "Business Intelligence - BI Aplicado à Gestão das Águas Subterrâneas". XVII Congresso Brasileiro de Águas Subterrâneas.

Pereira, G. S., Cavalcanti, B. S. (2016), "Siga: O Novo Sistema De Suporte À Decisão Para Gestão Dos Recursos Hídricos", p. 449-456. In: Anais do XIV Encontro Nacional de Estudantes de Engenharia Ambiental.

Vaisman, A, Zimányi, E., DW Systems Design and Implementation, Springer, 2014. 